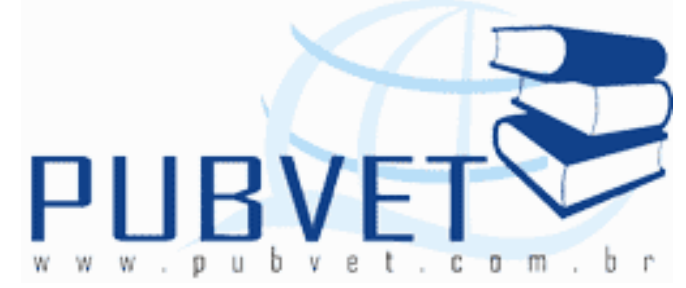

PUBVET, Publicações em Medicina Veterinária e Zootecnia.

\title{
Efeito de regimes de cortes sobre a produtividade e composição química do guandu (Cajanus cajan) em Porto Velho, Rondônia
}

\footnotetext{
Newton de Lucena Costa ${ }^{1}$, João Paulo Guimarães Soares ${ }^{2}$, Claudio Ramalho Townsend $^{3}$, Ricardo Gomes de Araújo Pereira ${ }^{3}$, João Avelar Magalhães ${ }^{4}$, Braz Henrique Nunes Rodrigues ${ }^{5}$
}

${ }^{1}$ Eng. Agr., D.Sc., Pesquisador da Embrapa Roraima. Boa Vista, RR.

2Zootec., D.Sc., Pesquisador da Embrapa Cerrados. Brasília, DF.

${ }^{3}$ Zootec., D.Sc., Pesquisador da Embrapa Rondônia. Porto Velho, RO.

${ }^{4}$ Méd. Vet., D.Sc., Pesquisador da Embrapa Meio-Norte. Parnaíba, PI.

${ }^{5}$ Eng. Agrícola, D.Sc., Pesquisador da Embrapa Meio-Norte. Parnaíba, PI.

\section{Resumo}

Os efeitos de frequências (40, 60 e 80 dias) e alturas de corte (60 e $90 \mathrm{~cm}$ ) sobre o rendimento de foragem e composição química do guandu (Cajanus cajan) foi avaliado em Porto Velho, Rondônia. Cortes realizados a cada 80 dias, a 60 ou $90 \mathrm{~cm}$ acima do solo, proporcionaram os maiores rendimentos de matéria seca e teores de cálcio. Os teores de nitrogênio, fósforo e magnésio não foram afetados pelos diferentes regimes de cortes. Os maiores teores de potássio foram verificados com cortes a cada 60 dias, independentemente da altura de corte. Cortes muito frequentes e a baixa altura mostraram-se inviáveis para o manejo do guandu, proporcionando baixos rendimentos de forragem e afetando negativamente a persistência das plantas. Visando 
conciliar rendimento e qualidade de forragem, o manejo mais adequado para o guandu consiste em cortes a intervalos de 80 dias e entre 60 e $90 \mathrm{~cm}$ acima do solo.

Termo para indexação: cálcio, fósforo, magnésio, matéria seca, potássio.

\title{
Effect of cutting regimes on forage yield and chemical composition of pigeon pea (Cajanus cajan) in Porto Velho, Rondônia
}

\begin{abstract}
The effect of cutting frequencies (40,60 and 80 days) and stubble height (60 and $90 \mathrm{~cm}$ ) on forage yield and chemical composition of pigeon pea (Cajanus cajan) were evaluated under field conditions, at Porto Velho, Rondônia. Cutting frequency at 80 days, with 60 or $90 \mathrm{~cm}$ stubble height, provided the higher dry matter yields and calcium contents. Nitrogen, phosphorus and magnesium contents were did not affected by cutting regimes. The higher potassium contents were obtained at 60 days cutting frequency, irrespective to stubble height. Frequents cutting, mainly at low stubble height, showed be inadequate to legume management. These data indicated that cutting frequency at 80 days, at 60 or $90 \mathrm{~cm}$ stubble height, were optimal for obtain higher yields with more forage quality.
\end{abstract}

Index terms: calcium, dry matter, magnesium, phosphorus, potassium

\section{Introdução}

O guandu (Cajanus cajan) é uma leguminosa arbustiva, perene de vida curta, que apresenta raízes profundas, característica que lhe confere excelente tolerância à seca (COSTA et al., 2007, 2009; MAIOR JúNIOR et al., 2009). Altamente palatável, produz elevadas quantidades de forragem com altos teores de proteína e minerais, notadamente em solos de alta fertilidade natural, sendo uma alternativa de baixo custo para a substituição parcial dos produtos comerciais comumente utilizados na suplementação animal (COSTA, 1996, 1999; MIZUBUTTI et al., 2007). 
No manejo de leguminosas arbustivas diversos parâmetros relacionados com a resposta morfofisiológica e a sobrevivência das plantas devem ser considerados, destacando-se o estádio de crescimento e a altura de corte em que são colhidas, as quais afetam marcadamente o rendimento e a qualidade da forragem (COSTA; OLIVEIRA, 1992a,b).

Em geral, o aumento do intervalo entre cortes resulta em incrementos significativos na produção de forragem, contudo, paralelamente, ocorre decréscimo em seu valor nutritivo (HIGUERA et al., 1998). De outro lado, a altura de corte é importante na rebrota pela eliminação ou não dos pontos de crescimento, pela área foliar remanescente e pela diminuição ou não das reservas orgânicas acumuladas durante os períodos favoráveis de crescimento (COSTA; SAIBRO, 1985; COSTA et al., 2009).

O presente trabalho teve por objetivo determinar a frequência e altura de corte mais adequadas para o manejo do guandu, nas condições edafoclimáticas de Porto Velho, Rondônia.

\section{Material e Métodos}

O experimento foi conduzido no Campo Experimental da Embrapa Rondônia, localizado no município de Porto Velho, durante o período de abril de 1996 a novembro de 1997. O clima da região é tropical úmido do tipo Am, com precipitação anual de $2.200 \mathrm{~mm}$, estação seca bem definida (junho a setembro); temperatura média anual de $24,9^{\circ} \mathrm{C}$ e umidade relativa do ar de $89 \%$.

O solo da área experimental é um Latossolo Amarelo, textura argilosa, com as seguintes características químicas: $\mathrm{pH}=5,2 ; \mathrm{Al}=2,2 \mathrm{cmol} / \mathrm{dm}^{3} ; \mathrm{Ca}+$ $\mathrm{Mg}=1,6 \mathrm{cmol} / \mathrm{dm}^{3} ; \mathrm{P}=3 \mathrm{mg} / \mathrm{kg}$ e $\mathrm{K}=69 \mathrm{mg} / \mathrm{kg}$.

O delineamento experimental foi em blocos casualizados com parcelas divididas e três repetições. As freqüências de corte $(40,60$ e 80 dias) representaram as parcelas principais e as alturas de corte $(60$ e $90 \mathrm{~cm}$ ), as subparcelas, as quais foram constituídas por quatro linhas de 5,0 m de comprimento, espaçadas de $1,0 \mathrm{~m}$ entre si. A cultivar de guandu utilizada foi a 
Preta. A adubação de estabelecimento constou da aplicação de 20 t/ha de esterco bovino e $50 \mathrm{~kg}$ de $\mathrm{P}_{2} \mathrm{O}_{5} /$ ha, sob a forma de superfosfato triplo.

Durante o período experimental foram realizados 10, 7 e 5 cortes, respectivamente para as freqüências de 40,60 e 80 dias. Após o corte da área útil, procedia-se a separação da fração utilizável (folhas, flores, vagens e ramos com até $6,0 \mathrm{~mm}$ de espessura) da fração grosseira (caules e ramos com diâmetro superior a $6,0 \mathrm{~mm}$ ), baseando-se no fato de que ramos mais espessos e fibrosos não seriam consumidos pelos animais.

As amostras referentes à fração utilizável como forragem foram colocadas em estufa à $65^{\circ} \mathrm{C}$, por 72 horas, para determinação dos rendimentos de matéria seca comestível (MSC). Posteriormente, as amostras foram moídas através de malha de $1,0 \mathrm{~mm}$ e preparadas para a quantificação dos teores de nitrogênio $(N)$, fósforo $(P)$, potássio $(K)$, cálcio $(\mathrm{Ca})$ e magnésio $(\mathrm{Mg})$.

\section{Resultados e Discussão}

A análise da variância revelou significância $(P<0,05)$ para a interação frequência $x$ altura de corte. Para as freqüências de corte de 40 e 60 dias, os maiores rendimentos de MS foram obtidos com cortes a $90 \mathrm{~cm}$ acima do solo, enquanto que para cortes a cada 80 dias não foi detectado efeito significativo $(P>0,05)$ da altura de corte. Independentemente da intensidade de utilização, cortes menos freqüentes foram os mais produtivos, sendo os maiores rendimentos de MS registrados com o intervalo entre cortes de 80 dias. Com cortes mais freqüentes e intensos, o desenvolvimento do guandu foi severamente prejudicado, o que implicou na obtenção dos menores rendimentos de forragem (Tabela 1 ).

Na região dos cerrados de Rondônia, Costa \& Oliveira (1992b) obtiveram um incremento de $89 \%$ no rendimento de forragem do guandu, efetuando cortes a cada 120 dias, em comparação com cortes a cada 30 dias. Resultados semelhantes foram reportados por Souza et al. (1991) e Costa \& Oliveira (1992a), que constataram que o melhor manejo para o guandu consistia em cortes a cada 120 dias e a $60 \mathrm{~cm}$ acima do solo. 
COSTA, N.L. et al. Efeito de regimes de cortes sobre a produtividade e composição química do guandu (Cajanus cajan) em Porto Velho, Rondônia. PUBVET, Londrina, V. 7, N. 2, Ed. 225, Art. 1491, 2013.

Tabela 1. Produção de matéria seca comestível (MSC) do guandu (Cajanus cajan), em função da frequência e altura de corte em Porto Velho, Rondônia.

\begin{tabular}{ccc}
\hline Freqüência de corte (dias) & Altura de corte $(\mathrm{cm})$ & MSC $(\mathrm{kg} / \mathrm{ha})$ \\
\hline \multirow{2}{*}{40} & 60 & $1.231 \mathrm{e}$ \\
& 90 & $1.758 \mathrm{~d}$ \\
\hline \multirow{2}{*}{60} & 60 & $2.123 \mathrm{c}$ \\
& 90 & $2.798 \mathrm{~b}$ \\
\hline \multirow{2}{*}{80} & 60 & $3.976 \mathrm{a}$ \\
& 90 & $4.435 \mathrm{a}$ \\
\hline
\end{tabular}

- Médias seguidas de mesma letra não diferem entre si $(P>0,05)$ pelo teste de Tukey

As concentrações de $\mathrm{N}, \mathrm{P}$, e $\mathrm{Mg}$ não foram afetadas $(P>0,05)$ pelos diferentes regimes de corte. Para os teores de $\mathrm{Ca}$ e $\mathrm{K}$ os maiores valores foram obtidos com cortes a cada 80 e 60dias, respectivamente, independentemente da altura de corte (Tabela 2). Em geral, as concentrações registradas neste trabalho são semelhantes ou superiores às relatadas por Xavier et al. (1991), Costa \& Oliveira (1992a,b) e Costa et al., (2007) para diversas cultivares de guandu. Quanto aos teores de $\mathrm{P}$, independentemente dos regimes de cortes adotados, foram superiores ou semelhantes ao nível crítico interno estimado por Costa $(1996,1999)$ para o guandu $(1,97 \mathrm{mg} / \mathrm{kg})$. Os teores de todos os macrominerais foram superiores ao nível crítico para bovinos de corte em crescimento $\left(11,21,8 ; 1,8 ; 1,0\right.$ e $6,5 \mathrm{~g} \mathrm{~kg}^{-1}$, respectivamente para $\mathrm{N}, \mathrm{P}, \mathrm{Ca}$, Mg e K) recomendados pelo National Research Council (2000).

Tabela 2. Concentração de macrominerais do guandu (Cajanus cajan), em função da frequência e altura de corte em Porto Velho, Rondônia.

\begin{tabular}{ccccccc}
\hline \multirow{2}{*}{$\begin{array}{c}\text { Freqüência de } \\
\text { corte (dias) }\end{array}$} & $\begin{array}{c}\text { Altura de } \\
\text { corte }(\mathrm{cm})\end{array}$ & $\mathrm{N}$ & $\mathrm{P}$ & $\mathrm{K}$ & $\mathrm{Ca}$ & $\mathrm{Mg}$ \\
\cline { 3 - 7 } 40 & 60 & $35,22 \mathrm{a}$ & $1,99 \mathrm{a}$ & $18,90 \mathrm{~b}$ & $4,02 \mathrm{c}$ & $3,22 \mathrm{a}$ \\
& 90 & $38,08 \mathrm{a}$ & $2,12 \mathrm{a}$ & $17,93 \mathrm{~b}$ & $4,22 \mathrm{c}$ & $2,64 \mathrm{a}$ \\
\hline \multirow{2}{*}{60} & 60 & $35,50 \mathrm{a}$ & $2,36 \mathrm{a}$ & $21,46 \mathrm{a}$ & $5,65 \mathrm{~b}$ & $3,57 \mathrm{a}$ \\
& 90 & $38,54 \mathrm{a}$ & $2,21 \mathrm{a}$ & $20,14 \mathrm{a}$ & $5,77 \mathrm{~b}$ & $3,60 \mathrm{a}$ \\
\hline \multirow{2}{*}{80} & 60 & $36,97 \mathrm{a}$ & $2,02 \mathrm{a}$ & $15,29 \mathrm{c}$ & $7,21 \mathrm{a}$ & $3,29 \mathrm{a}$ \\
& 90 & $37,21 \mathrm{a}$ & $1,97 \mathrm{a}$ & $14,87 \mathrm{c}$ & $7,54 \mathrm{a}$ & $2,98 \mathrm{a}$ \\
\hline
\end{tabular}

- Médias seguidas de mesma letra não diferem entre si $(P>0,05)$ pelo teste de Tukey 
COSTA, N.L. et al. Efeito de regimes de cortes sobre a produtividade e composição química do guandu (Cajanus cajan) em Porto Velho, Rondônia. PUBVET, Londrina, V. 7, N. 2, Ed. 225, Art. 1491, 2013.

\section{Conclusões}

1 - Cortes a cada 80 dias, a 60 ou $90 \mathrm{~cm}$ acima do solo, proporcionaram os maiores rendimentos de MS e teores de cálcio, além de assegurarem maior vigor de rebrota e persistência das plantas.

2 - Os teores de $\mathrm{N}, \mathrm{P}$ e $\mathrm{Mg}$ não foram afetados pelos diferentes regimes de cortes.

3 - Cortes frequentes e a baixa altura mostraram-se inviáveis para o manejo do guandu, proporcionando baixos rendimentos de forragem.

\section{Referências Bibliográficas}

COSTA, N. de L. Programa de pesquisa com pastagens em Rondônia. Porto Velho: Embrapa Rondônia, 1996. 24p. (Documentos, 32).

COSTA, N. de L. Adubação fosfatada na recuperação de pastagens degradadas da região amazônica. Macapá: Embrapa Amapá, 1999, 16p. (Documentos, 16).

COSTA, N. de L.; GIANLUPPI, V.; BRAGA, R.M.; BENDAHAN, A.B.; MATTOS, P.S.R.; VILARINHO, A.A.; OLIVEIRA, J.M.F. Alternativas tecnológicas para a pecuária de Roraima. Boa Vista: Embrapa Roraima, 2009. 35p. (Documentos, 19).

COSTA, N. de L.; OLIVEIRA, J.R.C. Cutting height affects Cajanus cajan yield and protein content. Nitrogen Fixing Tree Research Reports, Bangkok, v.10, p.119-120, 1992a.

COSTA, N. de L.; OLIVEIRA, J.R.C. Produção de forragem e composição química do guandu (Cajanus cajan cv. Preta) afetadas pela altura e freqüência de corte. In: REUNIÓN DE LA RED INTERNACIONAL DE EVALUACIÓN DE PASTOS TROPICALES - SABANAS, 1., 1992, Brasília. Memórias... Cali, Colombia: CIAT, 1992b, p.637-641.

COSTA, N. de L.; SAIBRO, J.C. Estabelecimento e regimes de corte de alfafa e Paspalum guenoarum sob cultivo estreme e consorciado. Pesquisa Agropecuária Brasileira, Brasília, v.20, n.12, p.1433-1442, 1985.

COSTA, N. de L.; TOWNSEND, C.R.; MAGALHÃES, J.A.; PEREIRA, R.G.A. Utilização estratégica das pastagens durante o período seco. PUBVET, Londrina, v.1, n.11, Art\#146, p.1-16, 2007.

HIGUeRA, A.; CASTILLO, A.; GARCÍA, C.; SOTO, I.; SANDOVAL, L.; LOBO, R. Efecto de la frecuencia y altura de corte sobre el rendimiento y calidad de forraje de diferentes variedades de quinchoncho, Cajanus cajan (L.) Millsp. Revista de la Faculdad de Agronomia (LUZ), v.15, n.2, p.188-198, 1998.

MAIOR JÚNIOR, S.G.S.; SOUTO, J.S.; SANTOS, R.V. dos; SOUTO, P.C. Produção de fitomassa do feijão guandu em diferentes arranjos populacionais. Tecnologia \& Cência Agropecuária, v.3, n.1, p.1-5, 2009.

MIZUBUTTI, I.Y.; RIBEIRO, E.L.A.; ROCHA, M.A.; MOREIRA, F.B.; KHATOUNIAN, C.A.; PEREIRA, E.S.; FERNANDES, W.C.; SOUZA, L. W.O.; PINTO, A.P. Consumo médio e digestibilidade do feno de capim Coast cross (Cynodon dactylon (L.)Pers.) e feijão guandu (Cajanus cajan (L.) Millsp.) em carneiros submetidos a dois regimes alimentares. Semina. Ciências Agrárias, v.28, p.513-520, 2007. 
NATIONAL RESEARCH COUNCIL. Nutrient requirements of beef cattle. $7^{\text {th }}$ ed. Washington: National Academy Press, 2000. 242p.

SOUZA, J.M.; CARBONERA, R.; VIAU, L.V.; DHEIN, R. Rendimento e qualidade de forragem do guandu (Cajanus cajan) no noroeste do RS. In: REUNIÃO ANUAL DA SOCIEDADE BRASILEIRA DE ZOOTECNIA, 28., 1991. João Pessoa. Anais... João Pessoa: SBZ, 1991. p.46.

XAVIER, D.F.; BOTREL, M.; ALVIM, M.J.; FREITAS, V.P. Altura e época de corte do guandu para produção de forragem na zona da mata de Minas Gerais. In: REUNIÃO ANUAL DA SOCIEDADE BRASILEIRA DE ZOOTECNIA, 28., 1991, João Pessoa. Anais... João Pessoa: SBZ, 1991. p.67. 